\title{
¿QUÉ INTERESES DEBEN DEFENDERSE?
}

\begin{abstract}
ANdrés Molina OCHOA ${ }^{1}$
RESUMEN: El artículo introduce dos problemas de la ética profesional de los profesionales del derecho: la titularidad de los derechos que deben representar los abogados y los objetivos que deben protegerse en el litigio. La discusión se centra en la representación que varias películas hacen del rol del abogado en los procesos y de sus obligaciones éticas y jurídicas frente a sus clientes.
\end{abstract}

PÁLABRAS ClAVE: ética profesional; cine; abogado; litigio.

\section{INTRODUCCIÓN}

Según Deck Schiffet (Danny Devito), uno de los principales personajes de la película The Rainmaker (Coppola, 1997)2, "Un abogado debe pelear por su cliente, abstenerse de robar algún dinero e intentar decir la verdad”. Para Deck, es fácil determinar las obligaciones éticas de los abogados, todo se limita a defender los intereses de sus clientes sin quebrantar unas normas mínimas de decencia.

La mayoría de códigos éticos para la abogacía coinciden en que uno de los pilares de la profesión es el deber de velar por los intereses de quienes representan. El artículo 2.7 del Código Deontológico de los Abogados de la Comunidad Europea, por ejemplo, establece que, "Sin

\footnotetext{
1 Máster y Doctor em Filosofía por la University of Binghamton - Nueva York (EE.UU.). Profesor de Filosofía en la University of Baltimore (EE.UU.) e nel John Jay College of Criminal Justice (EE.UU.). Abogado de la Universidad del Rosario en Bogotá (Colombia). Baltimore, EE.UU. E-mail: anmolina@jjay.cuny.edu

2 En español, Legítima defensa. Salvo pequeñas diferencias, la película es una versión fidedigna de J. Grisham (1995).
} 
perjuicio del debido cumplimiento de toda la normativa legal y deontológica, el Abogado tiene la obligación de actuar en defensa de los intereses de su cliente de la mejor manera posible, y debe anteponerlos a cualquier otro" (Comunidad Europea, 2015). En igual sentido, según el numeral 2 del artículo 4 del Código Deontológico de la Abogacía Española, "El abogado, está obligado a no defraudar la confianza de su cliente y a no defender intereses en conflicto con los de aquél” (España, [2001] 2015).

El objetivo de este artículo es ilustrar dos problemas éticos relacionados con la obligación de los abogados de velar por los intereses de los clientes, a partir de la representación que algunas películas hacen de su papel en la sociedad 3 . En especial, se analizan dos preguntas: ¿Quiénes son los titulares de los derechos que deben defender los abogados? y ¿cuáles son, precisamente, esos intereses que deben protegerse? Ambas preguntas son abordadas desde la perspectiva de la ética normativa ${ }^{4}$. La idea es indagar qué factores relevantes desde el punto de vista de la moral explican las diferentes obligaciones profesionales que los abogados tienen respecto de sus clientes.

Dos advertencias son necesarias antes de continuar con el artículo. La primera es que el objetivo es ilustrar dos discusiones éticas relacionadas con el ejercicio de la profesión jurídica y no proponer una solución a estos problemas. En otras palabras, el propósito es introducir dos importantes controversias que en ocasiones pasan desapercibidas, ocultas detrás del consenso general que existe sobre las funciones de los abogados. La segunda aclaración es metodológica: los problemas discutidos son éticos y se analizan desde esta disciplina. Por esta razón, las normas y jurisprudencias se citan solo com el objetivo de estudiar o ilustrar alguna

3 El cine y la televisión han sido foros en los que a menudo se discuten las soluciones a los diferentes dilemas éticos que enfrentan los abogados. Como afirma David Luban, "Series como L.A Law y The practice han hecho un trabajo respetable enseñando la ética jurídica a sus televidentes" (2007, p. 2).

4 Para Shelly Kagan: "La filosofía moral como un todo puede ser útilmente dividida en tres áreas básicas: metaética, ética normativa y ética aplicada. La ética normativa [...] consiste de proposiciones sustantivas relativas a cómo actuar, cómo vivir o qué tipo de persona ser. En especial, intenta plantear y defender los más básicos principios que gobiernan estos temas" (1998, p. 2). Esta y las otras traducciones son del autor. 
posición ética y no con el fin de establecer cuáles son los deberes jurídicos de los profesionales del derecho.

\section{EL PROBLEMA DE LOS CLIENTES}

Determinar quién es el cliente cuyos derechos deben representarse parece ser un problema sencillo. Si se es contratado, por ejemplo, para defender a un supuesto criminal, el interés que debe protegerse es el de quien está siendo acusado; por el contrario, si somos fiscales empleados por el Estado, será el de la sociedad. Por esta razón, es común preguntarse sobre la eticidad o no de los intereses de los clientes, mas no sobre quién es la persona cuyos derechos deben ser representados 5 . En la película The Rainmaker, Rudy Baylor (Matt Damon) pregunta a su contraparte Leo Drummond (Jon Voight), “¿Aún recuerda la primera vez que se vendió?”. Con su inquietud, Baylor afirma que hay pretensiones que no deben ser defendidas así el dinero recibido en contraprestación sea mucho, que no es ético utilizar el ordenamiento jurídico, como hace la compañía de seguros representada por Drummond, para negar reclamos legítimos a quienes no tienen la capacidad económica para contratar a un buen abogado. Baylor no cuestiona quién es el cliente de su contraparte, él sabe que es la compañía de seguros, lo que le preocupa es que esos intereses sean ilegítimos. En la segunda parte de este artículo se analizarán problemas similares a los planteados por Rudy Baylor en The Rainmaker; en la primera, se discutirá la pregunta sobre quién es el cliente cuyos derechos deben ser representados.

A pesar de ser casi olvidada por la teoría jurídica, esta discusión ha sido representada en varias películas. Una de ellas es The Verdict (Lumet, 1982), la historia de Frank Galvin (Paul Newman), un abogado cuya adicción al alcohol le ha hecho perder sus últimos casos y que, gracias a su amigo y antiguo socio Mickey Morrisey (Jack Warden), tiene la posibilidad de ganar un proceso fácil que permitiría solucionar la situación económica

\footnotetext{
5 Una importante excepción se encuentra en la obra de Ángel Osorio. Para él, "La cuestión esencial de los Abogados, que no es otra sino esta ¿A quién servimos? ¿A la sociedad o a nuestro cliente? ¿Somos voceros del interés público o del privado? ¿Debemos preocuparnos de que en la sociedad prevalezca el bien o de que gane el pleito nuestro patrocinador?” (Osorio y Gallardo, 1961, p. 14).
} 
en que se encuentra. El caso es el de una mujer en un coma causado por un error en la aplicación de la anestesia por parte de un médico perteneciente al Hospital de Boston. Frank es contratado por la hermana y el cuñado (Sally y Kevin Doneghy) de la mujer para que acepte una rápida conciliación por los daños causados. De esta forma, ellos podrán abonar 50 mil dólares al hospital y viajar a Tucson donde Kevin tiene una buena oferta de trabajo. Todas las partes en conflicto parecen ganar con un rápido acuerdo, el hospital evita la mala imagen que un juicio generaría en su contra, Frank recibe un tercio de la compensación, mientras que Sally y su esposo obtienen el dinero suficiente para poder pagar los gastos clínicos de su familiar y para viajar en busca de mejores oportunidades laborales.

Antes de iniciar el proceso, con el fin de preparar mejor su negociación con el hospital, Frank toma dos fotografías instantáneas a la mujer en coma. En ellas, por primera vez observa el rostro de la víctima. Algo sucede en ese momento, el abogado, hasta entonces solo preocupado por recibir el dinero que le correspondería por la compensación, enmudece mientras descubre una nueva verdad: no son Sally, ni Kevin por quienes él debe litigar; la razón para ir a juicio es la reparación de los derechos de aquella mujer a la que sólo se ha atrevido a observar detrás de un lente. Justo en ese instante, dos enfermeras lo increpan por encontrarse en un lugar prohibido para visitantes, Frank contesta entre asombrado y atemorizado por la magnitud de su nueva responsabilidad: "Yo soy su abogado".

A partir de su visita al hospital, Frank observa el caso desde una nueva perspectiva. Cuando el obispo Brophy (Edward Binns) le hace una oferta de 210.00o dólares para conciliar el caso - una suma casi tres veces superior a la que esperaba - Frank la rechaza, porque si la aceptara, "Nadie sabría la verdad”. Con esta decisión se evidencia que ahora Galvin no está preocupado por proteger los intereses de quienes lo contrataron, sino los de la víctima. Él prefiere defender el derecho a la verdad y no buscar una rápida conciliación como querían Sally y Kevin.

Apresurado por dejar la ciudad, Kevin no sólo rechaza la decisión de su abogado, sino que lo insulta cuando se lo encuentra:

Me ha arruinado la vida, señor. A mí y a mi mujer [...] No tiene que ir al hospital para ver a esa chica. Nosotros llevamos cuatro años haciéndolo. Durante cuatro años... 
mi mujer ha llorado todas las noches, por lo que le hicieron a su hermana [...] Soy un trabajador que intenta sacar a su mujer de aquí. Le contratamos y le pago ¿Y tengo que enterarme por la otra parte de que nos ofrecieron 200.000 dólares?

Para Kevin, Frank solo está obligado con quienes le contrataron, el bienestar de la mujer en coma únicamente debería importar si afecta los intereses de los representados. Sólo el contrato determina el ámbito de la asesoría jurídica, los únicos derechos que deben defender los abogados son aquellos que se han pactado.

¿Tiene la razón Kevin o Frank? ¿Quiénes son los titulares de los intereses que el abogado debe defender? ¿Cuál es la posición más correcta en este caso? La película parece apoyar la opción tomada por Frank; es decir, la posición según la cual, los abogados tienen la obligación ética de defender los derechos de las víctimas sin importar con quién se contrató la representación legal. Existen varios apartes en The Verdict que sugieren esta interpretación. En primer lugar, la escena antes descrita en la cual Frank por primera vez se identifica como apoderado de la mujer en coma, justo cuando él descubre la terrible situación en la que ella fue abandonada por las malas prácticas de los doctores. Las cámaras muestran a Clint Eastwood recitando una epifanía, una verdad profunda que ha descubierto al momento de su contacto con la víctima. Ahora será su abogado, no el de Kevin y Sally. En segundo lugar, el hecho de que Frank reivindique el derecho a la verdad y no el de la reparación como el más importante a hacer valer en el juicio ${ }^{6}$. Desde su encuentro con la mujer en coma, el abogado está más interesado en que se conozca la verdad de los hechos que en el dinero que podrían recibir sus representados.

Finalmente, porque la película se construye bajo la idea de que Galvin es capaz de recuperarse de su alcoholismo cuando decide luchar por una causa justa. Durante el filme, Frank es retratado como una persona ética que es incapaz de utilizar los métodos corruptos de su contraparte tales como acudir a los medios de comunicación para influir en la decisión de los

6 Frank comienza los alegatos de conclusión de la siguiente forma: "La mayor parte del tiempo, estamos perdidos. Decimos, por favor Dios dinos lo que está bien, cuál es la verdad. No hay justicia. Los ricos ganan, los pobres quedan impotentes. Nos cansamos de oír mentiras". 
jurados7. The Verdict construye la personalidad de Frank como un héroe caído en desagracia que se reencuentra con la virtud al decidirse a luchar8 por la opción más justa. La película nos invita a celebrar y no a condenar la decisión de Galvin, luchar por una víctima es una opción más correcta que defender llanamente a los representados.

Ahora bien, así la película sugiera lo contrario, existen muchas razones para apoyar la posición de Kevin y rechazar la de Frank. Uno de los deberes de los abogados es, precisamente, no defender intereses opuestos a los de sus clientes. En este sentido, el artículo 3.2.1. del Código Deontológico de los Abogados de la Comunidad Europea manifiesta que "El Abogado no deberá asesorar, ni representar, ni defender a dos o más clientes en un mismo asunto si existe un conflicto o riesgo significativo de conflicto de intereses" (Comunidad Europea, 2015)9. Desde esta perspectiva, es claro que Frank Galvin actuó de forma incorrecta al preferir defender los derechos de la mujer en coma a los de sus representados.

Para quienes defienden la posición de Kevin, en adelante teoría tradicional, la promesa hecha al celebrar el contrato - y no lo justo de lo discutido en el proceso - es la que determina quién es el titular de los derechos que deben proteger los abogados. Cuando reclama a Frank, Kevin

7 El problema de la relación entre los medios de comunicación y la estrategia legal será analizado adelante.

8 Uno de los aspectos más interesantes de la película está en la superación que Galvin hace de su autocompasión. Él se cree una víctima y por ello es incapaz de cumplir con sus deberes profesionales y de luchar contra los vicios que le están destruyendo su vida. Al inicio del filme, cuando Frank cree que todo está perdido, acude a su amante, Laura Fischer (Charlotte Rampling) buscando consuelo y llorando por haber cometido el error de rechazar la oferta del hospital. Laura no lo compadece, lo recrimina: "Quieres que te diga que es tu culpa. Puede que lo sea ¿Qué vas a hacer? [...] ¿Me iba a compadecer de ti? Te has equivocado de sitio. [...] Eres como un crío que viene un domingo por la noche. Quieres que te diga que tienes fiebre para que no tengas que ir al colegio". En los alegatos de conclusión, un Frank ya recuperado repite en sus palabras la lección que le aprendió a su amante: "Nos vemos como víctimas. Y nos convertimos en víctimas. Nos hacemos débiles. Dudamos de nosotros mismos, de nuestras creencias. Dudamos de las instituciones. Dudamos de la ley. [...] En mi religión, se dice actúa como si tuvieras fe y la fe te será otorgada. Si queremos tener fe en la justicia sólo tenemos que creer en nosotros mismos y actuar con justicia”. Frank actúa como si creyera que mediante el litigio puede obtener justicia para la mujer en coma. Es esta creencia, esta nueva fe la que le redime de sus vicios. Desde esta perspectiva, el rechazo a la oferta del hospital es la acción correcta que desencadenó los eventos que llevaron a Frank a superar su autocompasión.

9 De igual forma, según el artículo 3 del Statement of Client's Rights de la Bar Association de New York, "Usted tiene el derecho a que el consejo de su abogado sea independiente, profesional y juicioso, y a tener la lealtad de su abogado libre de cualquier conflicto de interés" (New York State Bar Association, 2015). 
lo hace en virtud del pacto celebrado, "Le contratamos. Le pago"; en otra palabras, "cumpla su parte de la promesa que yo he cumplido la mía". Para Kevin no es un problema que no haya una persona encargada de defender los intereses de la mujer en coma, para él, lo incorrecto es que el abogado por él contratado no represente sus intereses de la forma acordada.

La teoría tradicional se fundamenta en dos tesis sólidas: (1) las personas prometen algo al celebrar un contrato como el de la representación jurídica, (2) ceteris paribus, existe el deber moral de cumplir lo prometido. La primera tesis parece obvia, es claro que las partes se comprometen a realizar aquello que se obligan cuando celebran un contrato. De hecho, los dos conceptos tienen definiciones bastante parecidas; mientras el Código Civil español define al contrato en su artículo 1254 como un acto en el que "una o varias personas consienten en obligarse" (España, [1889] 2015) ${ }^{10}$, según Hart "Prometer es decir algo que crea una obligación para el promitente" (Hart, 1963, p. 54).

La segunda tesis es aceptada y defendida por la mayoría de escuelas éticas. Por solo citar dos filósofos, Kant utilizó precisamente el deber de obedecer las promesas para ilustrar lo que es un imperativo categórico ${ }^{11}$, mientras que W. D. Ross ejemplificó la noción de deberes prima facie con base en la obligación de honrar lo prometido: "Uno de los más evidentes hechos de nuestra conciencia moral es el sentido que tenemos de la santidad de las promesas" (Ross, 2002, p. 37) ${ }^{12}$.

\footnotetext{
${ }^{10}$ Definiciones iguales se encuentran en la mayoría de códigos y normativas. Así, por ejemplo el Código Civil (Code Napoléon) establece en su artículo 1101 que el contrato, "Es un convenio por el cual una o varias personas se obligan" (Francia, [1804] 2015). En todos ellos, se entiende el contrato como un acto en el cual las partes se obligan a algo.

11 “¿Podría yo decirme a mí mismo: cada cual puede hacer una promesa falsa cuando se halla en un apuro del que no puede salir de otro modo? Y bien pronto me convenzo de que, si bien puedo querer la mentira, no puedo querer, empero, una ley universal de mentir; pues, según esta ley, no habría propiamente ninguna promesa, porque sería vano fingir a otros mi voluntad respecto de mis futuras acciones, pues no creerían ese mi fingimiento, o si, por precipitación lo hicieren, pagaríanme con la misma moneda; por tanto, mi máxima, tan pronto como se tornase ley universal, destruiríase a sí misma" (Kant, 1942, p. 422).

12 La obligación de obedecer las promesas ha sido justificada por escuelas distintas a las de Kant y Ross. Autores consecuencialistas como Hume (1981, p. 516 y ss.) dedican varias páginas a justificar este deber desde su teoría ética (Pitson, 1988). Para una corta descripción de la discusión actual de la obligación de cumplir las promesas desde el consecuencialismo, ver Sinnott-Armstrong (2009, p. 438-442). Ahora bien, lo que las críticas al consecuencialismo sugieren no es que no exista la obligación de cumplir las promesas, sino que una teoría falla sino logra justificar este deber.
} 
Con base en los mismos fundamentos que los filósofos morales, algunos teóricos del derecho han considerado que al deber de cumplir los contratos subyace la obligación de honrar las promesas. En este sentido, Charles Fried ${ }^{13}$ afirma: "Al prometer, ponemos en las manos de otro hombre un nuevo poder para lograr su voluntad, aunque sea sólo un poder moral. Lo que él intentaba lograr por sí solo, ahora puede esperar que sea logrado con la prometida ayuda; darle ese nuevo poder era el objetivo de la promesa" (1982, p. 8).

¿Significa lo anterior que la teoría tradicional es válida y que no existe una razón ética para incumplir la promesa hecha al celebrar un contrato de representación legal? No, la decisión de Frank en The Verdict también tiene justificaciones sólidas. Es cierto que la teoría tradicional tiene una fuerte justificación moral, pero también lo es que hay motivos para dudar que sus conclusiones sean absolutas. Si bien es cierto que la mayoría de concepciones éticas consideran que existe un deber moral de honrar lo prometido, este jamás ha sido considerado absoluto ${ }^{14}$. En su ejemplo relativo al imperativo categórico, Kant ${ }^{15}$ se refiere al deber de no prometer lo que no podemos cumplir mas no a la obligación de respetar lo pactado en todas las circunstancias. Al denominar el deber de cumplir las promesas como una obligación prima facie, Ross también está aceptando que deja de existir bajo cierto tipo de circunstancias: "Sugiero deber prima facie o deber condicionado como una forma corta de referirse a la característica (muy diferente de ser un deber propio) que un acto tiene, en virtud de ser de cierta clase (por ejemplo de cumplir una promesa), de ser un acto el cual sería un deber propio si no existiera al mismo tiempo otro de otra clase que fuera moralmente significante" (Ross, 2002, p. 19).

El problema, por tanto, para quienes apoyan la tesis defendida en The Verdict, es probar que existen razones que invaliden el deber que tienen los

\footnotetext{
13 Sobre el fundamento ético de los contratos ver, entre muchos otros, Cohen (1933, p. 571583) y Fried (1982). En nuestro medio, ver Acosta Gómez (1999).

14 Piénsese, por ejemplo, en el célebre contraargumento que Sócrates ofrece a Céfalo al inicio de la República: "si alguno recibe unas armas de un amigo estando éste en su juicio, y ese amigo se las pide después de vuelto loco, todo el mundo diría que no debe devolvérselas y que no obraría en justicia devolviéndoselas [...]" (Platón, 1993, 331d). Lo correcto para Sócrates es incumplir lo pactado y no retornar las armas, dadas las nuevas circunstancias.

15 Ver supra 11.
} 
abogados con sus clientes de respetar la promesa hecha al momento de celebrar el contrato de representación legal. Una de ellas se encuentra en la normativa colombiana, en el artículo 28 de la ley 1123 de 2007 que ordena a los profesionales del derecho: "Defender y promocionar los Derechos Humanos"16. Si la función de los abogados es lograr la justicia o defender los derechos fundamentales, existe al menos una razón derivada del rol que los profesionales del derecho cumplen en la sociedad que puede justificar la acción de Frank Galvin.

Lo anterior no significa que los abogados tengan en todos los casos la potestad de atender intereses diferentes de quienes los contrataron, sino que hay razones por las cuales se justifica defender otro tipo de intereses. Si se acepta que los abogados tienen obligaciones distintas a la de representar a sus clientes -como por ejemplo reivindicar la justicia frente a una indefensa víctima- debe admitirse también que en algunas situaciones esta obligación es más importante que la de honrar el contrato de representación legal.

Ahora bien, existe una tercera posible tesis frente al tema en discusión, una que concilia en lugar de enfrentar los deberes para con los clientes y las obligaciones frente a la sociedad. Esta última posición parece ser la defendida por los redactores del Código Deontológico de los Abogados de la Comunidad Europea, el cual establece en su preámbulo que la misión del abogado

no se limita a ejecutar un mandato en el marco de la Ley. En un Estado de Derecho el Abogado es indispensable para la Justicia y para los justiciables, pues tiene la

\footnotetext{
${ }^{16}$ La Corte Constitucional colombiana, al respecto ha manifestado que: "En relación con los fines de la profesión, puede afirmarse que el legislador quiso dar relevancia especial a las función social que cumple el abogado, de forma que los fines de la profesión, expuestos en los artículos primero y segundo del decreto 196 de 1971 pueden ser complementados por algunos de los deberes establecidos en la Ley 1123 de 2007, tales como: observar la constitución y la ley (Artículo $1^{\circ}$ ), defender y promocionar los derechos humanos (Artículo $2^{0}$ ), colaborar en la realización de la justicia y los fines del Estado (Artículo 6 ${ }^{\circ}$ ) [...]" (Colombia, C-290/2008, 2015). Esta norma no ha sido excepcional en la tradición jurídica colombiana, el artículo 2 del decreto 196 de 1971 establecía que: "La principal misión del abogado es defender en justicia los derechos de la sociedad y de los particulares. También es misión suya asesorar, patrocinar y asistir a las personas en la ordenación y desenvolvimiento de sus relaciones jurídicas". Nótese que la principal función de los abogados es lograr la justica, la secundaria asesorar a sus clientes. De igual forma, según la ley $3^{\mathrm{a}}$ en su título 24 de la Novísima Recopilación de Indias: "[...] los abogados juren no ayudar en causas injustas, ni acusarán injustamente, y luego que conocieran que sus partes no tienen justicia, desampararán sus causas" (España, 1841, subrayo fuera de texto).
} 
obligación de defender los derechos y las libertades; es tanto el asesor como el defensor de su cliente.

Su misión le impone deberes y obligaciones múltiples, algunas veces con apariencia contradictoria, con respecto: Al cliente [...] Al público, para el cual una profesión liberal e independiente, regida por el respeto a las reglas que se ha impuesto a sí misma, es un medio esencial de salvaguardar los derechos del hombre frente al Estado y a los otros Poderes (Comunidad Europea, 2015).

La posición del código no contradice ninguna de las tesis estudiadas; acepta, como Frank Galvin en The Verdict, que los abogados están obligados con la sociedad en la garantía de los derechos humanos; sin embargo, no cree que este deber pueda entrar en una contradicción real para el código esta solo puede ser aparente - con la representación de los clientes. Frank obró mal al defender pretensiones diferentes a las de Sally y Kevin, pero no por quebrantar su promesa, sino porque la mejor forma que tiene la sociedad de lograr la justicia está en que los abogados representen con fidelidad los derechos de quienes los contrataron.

Un ejemplo común en las discusiones de la ética normativa ${ }^{17}$ puede ayudar a explicar esta posición intermedia. Imaginemos que Pedro llega a una clínica porque se ha fracturado su dedo meñique. En el mismo establecimiento, se encuentran tres personas que necesitan un trasplante para poder vivir; una requiere un corazón, otra un riñón y otra el hígado. Un médico descubre que la única forma de salvar la vida a estas tres personas es asesinar a Pedro y repartir sus órganos entre los demás pacientes. Aunque es posible pensar que la posición del galeno está justificada porque en un corto plazo produce más bienestar -si se hacen los trasplantes muere un paciente, pero se salvan tres, de lo contrario solo vivirá Pedro- en el largo plazo, si las clínicas repiten la acción hecha por el médico, los efectos serán nocivos porque la gente no acudirá a los hospitales por temor a que sean asesinadas para usar sus órganos.

The Verdict puede analizarse desde una perspectiva similar; aunque fuera cierto que la acción de Frank produce más bienestar al proteger los

\footnotetext{
17 Este caso es usado por los críticos de las éticas consecuencialistas. Una buena presentación del problema puede encontrarse en Kagan (1998, p. 67 y ss.). Una interesante visión de la discusión es la de John Harris (1975), quien utiliza las reflexiones del caso para proponer una lotería en la que se rife la obligación de donar los órganos que requieren otras personas para poder vivir.
} 
derechos de la principal víctima, en el largo plazo su acción será perjudicial porque nadie deseará contratar abogados si estos deciden defender los intereses de otras personas. En este sentido, no existe contradicción entre la teoría tradicional y la tesis que subyace a la posición de Frank; si él quiere que realmente se garanticen los derechos de las víctimas, debe representar de forma exclusiva los intereses de sus clientes. El error de Galvin, por tanto, no estaría en el principio ético que justifica sus acciones, sino en el método utilizado para honrarlo.

Existen dos problemas, sin embargo, con esta posición intermedia. El primero es que la analogía con el caso del médico es equivocada dada la diferente función que ambas profesiones tienen en la sociedad. Como afirma Ángel Ossorio, "Se nos confunde con los médicos. El médico debe asistir al que sufre, a todo el que sufre, sea quien sea. Pero nosotros no debemos defender al que litiga sino al que tiene razón para litigar. Pensando lo contrario se degrada nuestra profesión hasta los más abyectos extremos" (Ossorio y Gallardo, 1961, p. 25). Es plausible pensar que una sociedad en la cual los galenos causan la muerte a sus pacientes para salvar la vida a otras personas es una en la que nadie confiará en la medicina; por el contrario, es plausible creer que se protegen los derechos humanos de forma más eficiente en una sociedad en la cual los abogados se dedican a defender solo intereses que creen legítimos. En este sentido, el ejemplo de los trasplantes descalificaría el asesinato de Pedro, pero no la acción de Galvin. Dicho de otro modo, si por temor los pacientes no reciben atención médica no podrán garantizar su derecho a la salud; en cambio, si las personas que necesitan ser representadas legalmente saben que sus apoderados dejarán el caso si encuentran un interés desprotegido más legítimo, las personas seguirán acudiendo al litigio jurídico, solo que evitarán iniciar un proceso cuando su causa no sea justa.

El segundo problema está en la verificación empírica. No hay estudios que demuestren cuál sistema es mejor o cuál protege de forma más eficiente los derechos de las personas, si uno en el que los abogados defiendan de 
forma exclusiva los intereses de quienes los contrataron u otro diferente ${ }^{18}$. La necesidad de un estudio empírico es más urgente en el caso del derecho por cuanto, a diferencia de la medicina, las pretensiones que se dan en un proceso están en disputa. Lo normal es que los pacientes busquen la salud, un interés que es legítimo; en el derecho, las partes tienen pretensiones que en la mayoría de los casos son discutidas: librarse de una condena justa, escapar de alguna indemnización debida, etc. La comparación del caso de Pedro con The Verdict nos sugiere que generalizar el trasplante forzado de órganos llevará a la extinción de la medicina, pero no sucede lo mismo con la obligación de defender los derechos de las víctimas. La ausencia de estudios en este campo hace que la posición de los redactores del Código Deontológico de los Abogados de la Comunidad Europea sea solo una conjetura: a lo mejor si los abogados solo defienden los intereses de sus clientes la sociedad estará mejor.

Además de los anteriores inconvenientes, hay casos en los que una posición intermedia no es viable. En Judgments at Nuremberg ${ }^{19}$ (Kramer, 1961), el apoderado de los jueces alemanes acusados en el Tribunal de Nuremberg, Hans Rolfe (Maximilian Schell), se encuentra ante el dilema de proteger los intereses de Ernst Janning (Burt Lancaster) quien desea confesarse culpable de las atrocidades cometidas durante el régimen nazi, o los de sus otros representados. Avalar la confesión significaría agravar la condena de sus otros defendidos, pero no aceptarla implicaría ir en contra de los intereses de Janning. Rolfe no puede acudir a la posición intermedia porque cualquier determinación que tome irá en contra de uno de sus clientes. Aún más, tampoco puede acudir a la teoría tradicional porque

\footnotetext{
18 Existen algunas investigaciones que intentan dilucidar si el sistema acusatorio es más eficiente que el inquisitivo en descubrir la verdad en un proceso. Aunque útiles, estas investigaciones no se preguntan cuáles obligaciones deben asignárseles a los abogados respecto de sus clientes para una mejor garantía de los derechos de las personas en la sociedad. Lo más que se puede afirmar al respecto es que si las conclusiones a las que llegan los estudios son correctas, es preferible el sistema acusatorio para encontrar la verdad, pero esto no implica necesariamente que no sea posible uno mejor en el que los abogados tengan obligaciones con personas distintas a sus clientes (Thibaut, 1976; Damaska, 1975).

19 La película está basada en lo que se ha denominado como el juicio de los jueces oficialmente llamado Estados Unidos vs. Josef Altstötter et al. - el cual fue el tercer juicio llevado en Núremberg luego de la ocupación hecha por las tropas aliadas.
} 
inevitablemente quebrará la promesa hecha a sus representados, o bien defenderá los intereses de Janning o los de los otros acusados.

Ahora bien, el caso en Judgement at Nuremberg podría ser solucionado fácilmente si se contratara a otro abogado para defender los intereses de Janning. Algo similar puede decirse de The Verdict. Si el Estado pudiera asignar un profesional del derecho a todos aquellos que necesiten de asesoría legal, Frank Galvin habría podido dedicarse a velar por los intereses de Kelly y Sally sin que se vulnerasen los derechos de la mujer en coma. El problema está, sin embargo, en que esta no solo es una opción inviable, sino imposible, por lo menos en las circunstancias actuales $^{20}$.

La discusión hasta ahora planteada conduce a una conclusión, la solución al problema de la titularidad de los clientes depende de la posición que se tenga respecto a cómo debe el Estado atribuir el derecho a la asesoría legal. En nuestra sociedad, no hemos encontrado forma distinta de distribución de este derecho a la capacidad económica de las personas ${ }^{21}$. Quien puede pagar más tendrá, al menos en muchas ocasiones, la posibilidad de contratar a un mejor abogado. Salvo excepciones, si se posee dinero suficiente, se accederá a un buen representante legal que no esté atado a los compromisos u obligaciones propios de todo defensor de oficio. Si se carece de dinero, la defensa quedará a manos de la caridad, o de la capacidad del Estado de contratar buenos abogados.

Como afirma Russell Pearce, "[la Asociación norteamericana de colegios de abogados] se rehúsa a reconocer que nuestro sistema legal promete justicia igual según la ley, pero permite que sea vendida $\mathrm{y}$ comprada" (Pearce, 2004, p. 969). Si Kevin y Sally no estuvieran necesitados de dinero, habrían podido contratar a un abogado que velara por los intereses de su parienta en lugar de buscar una rápida conciliación para mejorar sus condiciones laborales.

\footnotetext{
${ }^{20}$ Estudios demuestran que las sociedades jamás podrán tener los recursos necesarios para proveer servicios legales a toda su población (Bellow; Kettleson, 2005).

${ }^{21}$ Hay varias organizaciones que brindan asesoría gratis, no obstante, las necesidades de las personas no es satisfecha con este tipo de instituciones. Para un recuento de las organizaciones que prestan este servicio en Colombia (Tobón Franco, 2008, p. 88 y ss.).
} 
El problema de la asignación de la representación jurídica ha sido discutido de forma amplia en el cine. En Dead Man Walking (Robbins, 1995), por ejemplo, el abogado defensor Hilton Barber (Robert Prosky) de un condenado a muerte demuestra que a diferencia de su representado, el otro acusado del delito de homicidio y violación logró escapar de la pena capital por poder pagar a un mejor abogado. En The Rainmaker, Rudy Baylor manifiesta desesperado al creer que no podría ganar su caso frente a los famosos abogados contratados por la compañía aseguradora: "Hay más de cien años de experiencia legal sentada en esta mesa. Mi único personal ha perdido seis veces el examen para obtener la tarjeta profesional".

¿Es esta situación injusta? ¿Es injusto que acceder a la asesoría legal dependa de la capacidad económica de las personas? Quienes defienden la tesis de The Verdict creen que otra forma de adjudicación de la representación jurídica es no solo posible, sino obligatoria desde el punto de vista de la ética. Los abogados tienen la obligación de defender fundamentalmente los derechos de las víctimas y no solo los de aquellos que tienen suficiente dinero para contratarlos. Para esta posición, es correcta la opción de Galvin, su acción contribuyó a que el derecho a la verdad de la mujer en coma fuera respetado en el juicio. Para los defensores de la teoría tradicional, en cambio, la única función de los abogados es representar a sus poderdantes dentro del marco legal.

La discusión sobre quién es el cliente a quien deben representar los abogados nos ha conducido a una pregunta diferente, ¿Cuál es la mejor forma de distribuir el derecho a la asesoría legal? Como se manifestó al inicio del artículo, el objetivo es solo ilustrar un problema que en ocasiones ha pasado desapercibido por la teoría jurídica, no solucionarlo. En todo caso, parece claro que una mayor argumentación desde el punto de vista de la ética ${ }^{22}$ y de las ciencias sociales es necesaria para defender las dos tesis planteadas.

\footnotetext{
${ }^{22}$ Existen otros argumentos éticos que sustentan la teoría tradicional y que no se han incluido en el artículo por problemas de tiempo y espacio. Una opinión muy interesante es la de Clyde Spillinger (2005) quien sostiene que los abogados deben ser fieles a sus clientes con base en lo que denomina engagement, compromiso, es decir en la obligación que tienen de hacer suyas las demandas de sus representados.
} 
Pese a que las posiciones estudiadas aparecen como contradictorias, ambas tienen en algo en común, el respeto por el sistema jurídico vigente. Tanto la tesis tradicional como la defendida en The Verdict sostienen que el mejor lugar para dilucidar los conflictos es el litigio. Pueden existir controversias sobre quién es la persona que debe ser defendida, pero no sobre la idoneidad del derecho para dirimir los conflictos que se dan entre los individuos.

Existen doctrinas que no aceptan estas premisas. Al contrario, afirman que el derecho no es un sistema neutral sino un campo de batalla en el que las luchas de clases, de facciones y de género continúan sus pugnas. La función de los abogados no es la defensa de los intereses de los clientes, sino la transformación del ordenamiento jurídico que produce dicho tipo de conflictos. Esta posición será analizada en el siguiente acápite relativo a los intereses que deben ser defendidos.

\section{LOS INTERESES DE LOS CLIENTES}

En la película Adam's Rib (Cukor, 1949), la abogada Amanda Bonner (Katharine Hepburn) dirige la defensa de su cliente acusada de intento de homicidio, Doris Attinger (Judy Holliday), a concienciar a la sociedad del trato desigual que sufren las mujeres en el sistema jurídico norteamericano y no solo a evitar una sentencia condenatoria. En una de las primeras escenas, Amanda explica a su esposo y fiscal encargado del caso Adam Bonner (Spencer Tracey), el motivo que la llevó a aceptar la defensa: “¿Por qué dejar que este deplorable sistema se filtre en nuestras cortes judiciales en donde se supone que las mujeres son iguales?”

La posición de Amanda en la película es apoyada por algunos autores quienes consideran que en el litigio jurídico se reproducen las prácticas de dominación que se dan en la sociedad. Para no ser cómplices de la opresión que puede ser fomentada por el derecho, los abogados deben no solo defender los intereses del cliente, sino utilizar los juicios para visualizar las contradicciones internas de la sociedad. En este sentido, Peter Gabel y Paul Harris manifiestan que "Un primer principio de una práctica contrahegemónica debe ser subordinar la meta de proteger los derechos de la 
gente a la de construir una auténtica o no alienada consciencia política" (Gabel y Harris, 1982-1983) 23.

Un interés similar al sugerido por Gabel y Harris puede verse en la actitud de Amanda a lo largo de Adam's Rib, y en especial en el siguiente diálogo que mantiene con su secretaria:

- ¿Qué piensas de un hombre que es infiel a su esposa?

- No está bien, pero....

- Bueno, y ¿Qué piensas de una esposa que le es infiel a su marido?

- Eso es algo terrible [...]

- ¿Por qué la diferencia? ¿Por qué No está bien, si él lo hace, pero es algo terrible si ella es la que lo hace?

- No hago las reglas

- Seguro las haces, todos las hacemos. Un hombre hace una $\mathrm{u}$ otra jugarreta y el mundo entero le hace un guiño, una mujer hace lo mismo y hay un escándalo.

Mediante la conversación con su secretaria, Amanda logra dos objetivos importantes. En primer lugar, libera a la lucha por la igualdad de la mujer de lo que Sen ha llamado la encarcelación de los derechos humanos, su confinamiento en el sistema judicial24 (Sen, 2004, p. 319). La abogada es consciente que pese a lo importante del litigio, este no es suficiente para solucionar los problemas de inequidad en la sociedad; es necesario, además, un cambio en la cultura, en la forma de entender las relaciones entre ambos géneros. En segundo lugar, revela las contradicciones internas que el ordenamiento jurídico esconde al consagrar una igualdad ante la ley que será ignorada en la práctica.

El derecho es un instrumento eficaz para el ocultamiento de las contradicciones propias de la sociedad dado que, como manifiesta Robert Gordon, "los discursos legales están saturados con categorías e imágenes que en una miríada de sutiles formas racionalizan y justifican el orden social como natural, necesario y justo" (2006, p. 214). La acción de Amanda desacraliza el lenguaje jurídico y revela como contingente y contradictorio

\footnotetext{
23 En igual sentido, ver Gordon (1988).

24 "La implementación de los derechos humanos debe ir también más allá de la legislación, una teoría de los derechos humanos no puede ser confinada sensiblemente dentro del modelo jurídico en el que es frecuentemente encarcelada. Por ejemplo, el reconocimiento público y la agitación (incluyendo el monitoreo de las violaciones) puede ser parte de las obligaciones -a menudo imperfectas- generadas por el reconocimiento de los derechos humanos" (Sen, 2004, p. 319-320).
} 
lo que el derecho ha disfrazado como sagrado y necesario. Lo natural se convierte en artificial, lo que permite pensar en órdenes sociales diferentes.

En una de las escenas más famosas de la película, Adam reclama a Amanda por su posición respecto del caso:

\begin{abstract}
Veo en ti algo que no había visto antes y no me gusta. De hecho, lo odio, desprecio por la ley, eso es lo que tienes, una enfermedad contagiosa. Crees que la ley es algo que puedes superar o evitar, o simplemente de lo que puedes alardear. Empiezas con eso y terminas... bueno... iMira lo que nos pasa! La ley es la ley, bien sea buena o mala. No sólo es malo quebrarla, lo es también cambiarla. Empiezas con una ley, luego muy rápido todas las leyes, luego todo.
\end{abstract}

Adam ve a la sociedad, como afirma Gordon, con categorías naturalizadas, petrificadas e inmodificables. Para él, querer cambiar la ley y la sociedad no es un ideal sino una enfermedad contagiosa que debe combatirse. Esta visión del mundo esconde la opresión que sufren algunos miembros de la sociedad - en este caso las mujeres - y, al mismo tiempo, hace creer que es imposible cualquier tipo de cambio. Al defender el status $q u o$, al criticar cualquier persona que desee modificar algunas de las estructuras del sistema, Adam está apoyando, quizás sin querer, un ordenamiento jurídico que oprime a la mujer.

La estrategia procesal seguida por Amanda en el proceso obedece también a su preocupación por modificar las estructuras sexistas de la sociedad. Doris es una mujer golpeada de forma constante por un marido que, además, le es infiel. El grado de frustración en que se encontraba la llevó a perder la capacidad de autodeterminación. Cuando quiere describir lo que sucedió antes de la comisión del crimen, manifiesta: "Yo no decidía nada. Todo lo hacía como si estuviera en un sueño, como si me viera a mí misma pero sin posibilidad de hacer nada -como en un sueño". Así las cosas, la estrategia más fácil sería invocar alguna causal de inculpabilidad que atenuara la pena como ira o intenso dolor. No obstante, ni Amanda, ni Doris están de acuerdo con seguir este tipo de defensa porque, como afirma la acusada: "No fue un accidente. Yo quería dispararle". Decir que Doris estaba perturbada mentalmente es aceptar que obró mal y que no hay nada erróneo con el sistema social. Por esta razón, Amanda ensaya una defensa basada, según sus propias palabras, “[...] en la proposición según la cual todas las personas del género femenino deben ser tratadas ante la ley como 
iguales a las personas de género masculino”. De esta forma, no solo se busca lograr la libertad para Doris -lo cual quizás sería más fácil de conseguir apelando a una causal de inculpabilidad- sino mostrar las estructuras del sistema que permiten que la vida de mujeres como Doris sea miserable.

La defensa realizada por la abogada en Adam's Rib coincide con una de las más estudiadas y analizadas por el feminismo (Gabel y Harris, 19821983; Shalter, 1976; Garry y Goldberg, 1977, p. 217-241; O'Donovan, 1989; MacKinnon, 1982). En marzo de 1974, 20 minutos después de ser violada por dos hombres, Inez García busca a sus victimarios y asesina a uno de ellos. Charles Garry, su primer abogado, fundamentó la defensa en la incapacidad mental de García, lo que propició un litigio exitoso para la acusada, al menos desde los parámetros tradicionales del litigio. Inez García fue condenada por homicidio en segundo grado, un delito con una pena favorable teniendo en cuenta la gravedad de sus acciones.

La estrategia llevada a cabo por Charles Garry fue equivocada, sin embargo, desde el punto de vista de Inez García y de los objetivos del naciente movimiento feminista (MacKinnon, 1982). La defensa no tuvo en cuenta la opinión de la acusada quien nunca consideró que había obrado mal o que no estaba en sus condiciones mentales cuando asesinó a su violador. Al respecto, Inez García manifestó: "No lamentó lo que hice. De lo único que me arrepiento es que falle en darle a Luis" (Gabel y Harris, 19821983). Además, la estrategia contribuyó a que el proceso se centrara en el delito cometido por Inez y no en la violación de la que fue víctima. De esta forma, se legitimó un discurso dominante que oculta las agresiones que sufren las mujeres.

En un segundo proceso, Inez contrata a una abogada feminista, Susan Jordan, quien alega legítima defensa en lugar de la causal de inculpabilidad que se había esgrimido en el primer juicio. La idea era "traducir la regla de legítima defensa, masculinamente orientada, en una forma que capturara la experiencia de una mujer enfrentando un ataque posible por un hombre" (Gabel y Harris, 1982-1983, p. 382). Pese a que la estrategia judicial más segura para Inez y para Doris era apelar a una causal de inculpabilidad, ambas prefieren otro tipo de defensa, uno que se base en afirmar la corrección de su acción y no la debilidad mental de la acusada. De esta 
forma, sus procesos sirven no sólo para lograr su inocencia, sino para reivindicar los derechos de las mujeres que pudieran estar en un grado similar de opresión.

La legítima defensa solo puede esgrimirse cuando el acto imputado se ha realizado ante una agresión inminente, sin embargo Inez García asesinó a su violador 20 minutos después de haberse cometido el delito. Lo interesante de la estrategia usada por Susan Jordan es que evidencia que esta concepción de la causal de justificación es sexista, dado que desconoce que la violencia que sufre una mujer violada no termina al momento de padecer la agresión física, sino que continúa mientras dura el ataque sicológico. Consagrar la legítima defensa solo desde una perspectiva masculina implica discriminar a la mujer.

La estrategia diseñada por Susan Jordan fue exitosa también porque hizo que la violación desplazara al homicidio en el debate público. El problema ya no era el crimen cometido por una persona en incapacidad de determinación, sino las múltiples agresiones que padecen las mujeres en la sociedad norteamericana. Como afirma Katherine O’Donovan:

\begin{abstract}
El acto de la violación se convirtió en el centro del juicio. Las experiencias de las mujeres violadas estuvieron presentes ante el jurado. Se revirtieron las relaciones de poder presentes en el primer juicio. Esto permitió al jurado escapar de una decisión meramente formalista basada en la práctica del derecho existente, y tomar una decisión basada en la presentación de una perspectiva que usualmente no es tomada en cuenta (1989, p. 136).
\end{abstract}

Tanto en el caso real de Inez García, como en el ficticio de Adam's $R i b$, las abogadas utilizaron el derecho no sólo para lograr la libertad de sus clientes, sino para cambiar aquellas estructuras de la sociedad que convirtieron a sus clientas en víctimas. Para ello, como se explicó al inicio de este acápite, desencarcelaron los derechos del litigio jurídico y lo llevaron a una dimensión distinta, una en la que la sociedad puede discutir, reflexionar y darse cuenta de las inequidades del sistema.

La idea de utilizar al litigio jurídico como un escenario en el cual la sociedad puede descubrir sus propias injusticias es común en el cine y en la historia del derecho. Inherit the Wind (Kramer, 1960), por ejemplo, describió el famoso juicio a Scopes (Tennessee [1925] 2015), para atacar al macartismo y defender el derecho a la libertad de expresión (Larson, 1997, 
p. 238 y ss.). A su vez, el juicio a Scopes fue utilizado en 1925 para defender la enseñanza de la teoría de la evolución en el estado de Tennessee (Crompton, 2010). En Colombia, Guillermo Prieto, un famoso presentar de televisión conocido como Pirry, hizo un documental sobre Luis Alfredo Garavito, acusado de la violación y asesinato de más de 140 niños, con el fin de: "conformar un frente para exigir respuesta estatal" (Prieto, 2006). Una vez la gente conoció los pormenores del caso y la condena que se le imputó a Garavito, se creó una red social para exigir mayores condenas a los violadores, así como mayor protección a los menores de edad.

Ahora bien, es claro que es necesario trasladar lo discutido en el juicio al debate público para que estrategias como la de Amanda Bonner y Susan Jordan sean exitosas. Gracias al proceso, la opinión nacional no sólo conoce las contradicciones internas de la sociedad, sino que se convierte en un mecanismo de presión para que la decisión tomada sea justa. Tanto Doris Attinger en Adam's Rib como Inez García fueron apoyadas por los medios de comunicación y por movimientos feministas que estaban de acuerdo con su causa.

¿Es ética esta estrategia? ¿Es correcto apelar a la opinión nacional para que genere un cambio en la estructura de la sociedad y en la decisión de los jueces? Contrario a lo que podría pensarse, esta estrategia es común en el cine. En In the Name of the Father (Sheridan ,1994), la abogada, Gareth Peirce (Emma Thompson) utiliza la presión pública para lograr un segundo juicio para su defendido Gerry Conlon (Daniel Day-Lewis) ${ }^{25}$. A medida que las marchas a favor de Conlon crecen en el filme, la posibilidad de reabrir el caso aumenta. De igual forma, en Miracle on 34th Street (Seaton, 1947), la decisión a favor de la cordura de Kris Kingle (Edmund Gwenn) está mediada, en gran parte, por el apoyo de miles de niños que se niegan a creer que Santa Clause es un personaje ficticio y que ven en el anciano la prueba de sus creencias.

\footnotetext{
${ }^{25}$ La película está basada en el caso de los cuatro de Guildford, injustamente acusados en participar en atentados perpetrados por el IRA.
} 
Existen, sin embargo, otras películas que representan como inmoral utilizar a la opinión nacional para presionar una decisión legal. En The Verdict, Frank Galvin deliberadamente se opone a las prácticas de su contraparte Ed Concannon (James Mason) de acudir a la presión pública para obtener una decisión favorable para su cliente. "Son sus métodos, no los míos”, le dice a su socio, cuando éste le cuenta que Concannon ha hecho publicar varios artículos a favor de los médicos acusados en el juicio.

Un caso interesante es la historia real de Sacco y Vanzetti ${ }^{26}$ llevada al cine por Giuliano Montaldo en 1971. El defensor durante el segundo juicio a los anarquistas italianos, Fred Moore, se caracterizó por intentar politizar el proceso. Gracias a la divulgación que hizo del caso, de forma rápida se creó un movimiento para apoyar a Sacco y Vanzetti. Famosos intelectuales como John Don Passos y Albert Einstein protestaron la condena a muerte de quienes se convertirían en dos de los más famosos presos políticos de la historia. No obstante, la estrategia de Moore no surtió el efecto jurídico esperado; de hecho, desesperado al ver que el juez Webster Thayer le negaba todas sus peticiones, abandonó la defensa en manos del abogado William Thompson.

Moore era un abogado radical que había hecho toda su carrera en California y que desconocía el procedimiento del estado de Massachusetts, donde Sacco y Vanzetti estaban siendo juzgados ${ }^{27}$. Quizás por esta razón, decidió fundamentar su litigio en la presión pública y no en argumentos jurídicos. Ahora bien, aunque no puede negarse que el veredicto final en contra de los dos acusados estaba mediado en gran parte por la persecución que el movimiento anarquista sufría en el momento ${ }^{28}$, las actuaciones de

\footnotetext{
${ }^{26}$ Entre las muchas fuentes sobre el proceso llevado en contra de los dos anarquistas italianos ver la película Sacco and Vanzetti (Miller, 2006) y el libro de Bruce Watson (2007).

${ }^{27}$ El mismo Fred Moore ([1921] 2015) reconocía ese hecho, en sus alegatos de conclusión manifestó: "Tres mil millas de distancia nos separa a los del Pacífico de ustedes, los del Atlántico; naturalmente, esas millas han desarrollado variaciones peculiares en la práctica, en el procedimiento. Las condiciones locales han desarrollado prácticas locales que, en cierta medida, varían de las prácticas del Atlántico”.

${ }^{28}$ En 1977, el entonces gobernador del Estado de Massachusetts, Robert Dukakis, ordenó una investigación sobre el caso, la cual concluyó que "Sacco y Vanzetti fueron injustamente procesados y ejecutados". El reporte entero puede encontrarse en Sinclair (1978).
} 
William Thompson sugieren que un mejor resultado hubiera sido posible, quizás evitar la silla eléctrica, con una defensa más ortodoxa.

La estrategia utilizada por Moore en Sacco y Vanzetti fue exitosa como instrumento de difusión del movimiento anarquista ${ }^{29}$, pero no lo fue como defensa de los acusados. Lo anterior nos lleva a una pregunta, ¿Es correcto someter los intereses de los clientes a otros más justos? ¿Es ético sacrificar una defensa táctica por una que obtenga mayores réditos políticos?

Autores como Gordon, Harris y Gabel hacen parte de un grupo más extenso que pretende ampliar el tipo de intereses que deben tener en cuenta los abogados, al momento de representar a sus clientes. Aunque todos los teóricos mencionados hacen parte del movimiento conocido como los Estudios Críticos del Derecho ${ }^{30}$, existen otros que desde perspectivas no solo diferentes sino opuestas, defienden la misma tesis. En Colombia, por ejemplo, Natalia Tobón afirma que "Los abogados tienen la función social de defender en justicia los intereses de la sociedad; esa función prevalece sobre la asesoría y asistencia que se brinda a los particulares en sus relaciones jurídicas" (Tobón Franco, 2008 p. 72)31.

Otros autores, sostienen una posición contraria, en adelante tesis de la fidelidad, según la cual los abogados deben limitarse de forma exclusiva a la defensa de los intereses de sus clientes. En este sentido, John Finnis afirma que: "[los abogados] tienen el deber de promover el bien común, aunque la primera forma en que lo logran es promoviendo la verdad, así como los intereses propios y los derechos legales individuales de sus clientes, según la ley y las reglas de conducta profesional. Intrínseco al bien común está el interés público de la protección de los derechos privados” (Finnis, 1999, p. 52). Quienes suscriben esta tesis, no afirman que sea admisible cualquier tipo de conducta con tal de obtener un mejor resultado

\footnotetext{
${ }^{29}$ Sobre el juicio de Sacco y Vanzetti han escrito autores como Upton Sinclair, John Dos Passos y Mauricio Kartún. Músicos como Joan Baez, Georges Moustaki y Peter Seeger han compuesto canciones en honor de los dos anarquistas italianos. Howard Zinn, el famoso historiador y anarquista estadounidense, realizaba conferencias sobre el significado del juicio a Sacco y Vanzetti hasta antes de su muerte en 2010.

30 Para una introducción al movimiento de los estudios críticos del derecho, ver Kelman (1987); Perez Lledó (1996); y Molina Ochoa (2014).

${ }^{31}$ Para autores con posiciones similares, ver Luban (2007); Shaffer (1985); y Simon (2000).
} 
para sus representados ${ }^{2}$, lo que sostienen es que dentro de un marco legal y ético, los únicos intereses que deben defenderse son los de los clientes.

Existen al menos dos tipos de argumentos que los defensores de la tesis de la fidelidad esgrimen. Unos son consecuencialistas ${ }^{33}$ y se refieren al tipo de resultados que pueden preverse si los abogados comienzan a defender intereses que pueden ir en contravía con los de sus clientes. El segundo tipo de argumentos se relacionan con la función que los abogados tienen en la sociedad, con lo que Thomas Nagel ha llamado la división ética del trabajo, es decir la tesis según la cual "las restricciones de la moral pública no son impuestas en su totalidad de la misma forma a todas las acciones públicas o a todos los cargos públicos” (Nagel, 1991, p. 80).

En el primer acápite de este artículo, se discutieron argumentos consecuencialistas en lo relacionado a la titularidad de los intereses que deben defender los abogados. Entonces, se afirmó que no se había probado de forma definitiva que el mejor sistema legal es aquel en el cual los profesionales del derecho sólo están obligados para quienes los contrataron. Lo mismo puede afirmarse de la pregunta sobre el problema de qué tipo de intereses deben defenderse. En realidad, no poseemos información que nos permita determinar qué obligaciones deben imponerse a los abogados para que el sistema jurídico produzca una mejor justicia. No sabemos qué sucedería en un ordenamiento en el que, por ejemplo, existiera la obligación de alegar aquellos hechos que pueden perjudicar a los clientes, si con ello se logra honrar un valor más importante.

Aun si se acepta la tesis de la fidelidad, es difícil determinar cuál es su límite, cuál es el marco jurídico dentro del cual los abogados deben defender los derechos de sus clientes. Parece claro, por ejemplo, que no es ético falsificar una prueba para lograr una declaración de inocencia, pero

\footnotetext{
${ }^{32}$ El límite de lo permitido y lo prohibido, no obstante, varía según el nivel de fidelidad que se le exige a los abogados respecto de sus clientes. Monroe Freedman, por ejemplo, defiende la actuación de un abogado que para proteger a su cliente, no solo ocultó información sobre donde se encontraban las víctimas, sino que mintió al padre de una de ellas sobre si sabía si su hija estaba viva. La posición de Freedman, no obstante, es polémica entre autores que defienden lo que se ha denominado aquí como tesis de la fidelidad (Freedman, 1975; Luban, 1988). Una descripción del caso puede encontrarse en el artículo "The law: A question of confidence", publicado en el Time (1974).

33 El consecuencialismo puede ser definido como aquella escuela según la cual los resultados de una acción son los únicos factores relevantes para juzgar su eticidad (Kagan, 1998, p. 59 y ss.).
} 
existen casos en los cuales las respuestas no son tan evidentes ${ }^{34}$. En la película Priest (Bird, 1995), Lisa Unsworth (Christine Tremarco) confiesa al sacerdote Greg Pilkington (Linus Roache) que es abusada por su padre. Pese a varios intentos, el presbítero falla al intentar hacer que la menor revele lo sucedido a su madre. El problema se agrava cuando el autor del crimen se confiesa por el grave delito cometido ¿Debe el sacerdote vulnerar el secreto de confesión y relatar lo acontecido a la policía? ¿Es más importante su deber como presbítero que su obligación de respetar y proteger los derechos de las menores?

La Corte Constitucional colombiana declaró en sentencia C-411 de $1993^{35}$, la inexequibilidad del artículo 284 que establecía como límite del secreto profesional que se tratara de "circunstancias que evitarían la consumación de un delito futuro". Para la Corte es claro que: “[c]omo en el caso del derecho a la vida, en el del secreto profesional la Carta no dejó margen alguno para que el legislador señalara bajo qué condiciones puede legítimamente violarse un derecho rotulado inviolable" (Colombia, C411/1993, 2015). Si pudiera equipararse los deberes de un sacerdote con los de un abogado, para el Tribunal Constitucional es claro que Greg hizo lo correcto al no revelar las violaciones que padecía Lisa.

¿Es mejor un sistema jurídico en el que el secreto profesional se protege de forma absoluta? ¿Garantiza mejor los derechos una normativa en la cual los abogados están solo obligados a defender los intereses de sus clientes? ¿Es mejor un sistema en el cual acusados como Sacco y Vanzetti reciben una representación legal cuyo fin es la modificación del ordenamiento jurídico y no la libertad de los procesados? Las respuestas a estas preguntas demandan un tipo de investigación que no solo sobrepasa los límites de este trabajo, sino que no se ha realizado. En los casos de Inez García y Doris Attinger, el curso de acción a seguir en el proceso no ofrecía mayores dificultades, porque las intenciones de las acusadas coincidían con los intereses políticos que se buscaban en el litigio. Algo similar puede decirse de Sacco y Vanzetti, aunque en este proceso las consecuencias,

\footnotetext{
34 Ver supra 32.

35 Para la normativa sobre el secreto profesional de los abogados en Colombia, ver Tobón Franco (2008, p. 226 y ss.).
} 
quizás, podrían haber sido menos perjudiciales para los acusados de haber existido otro tipo de defensa. En el caso de Priest, la decisión de respetar el secreto profesional produjo consecuencias negativas, no solo para la víctima sino para toda la comunidad que integraba la parroquia.

La lectura de todos estos casos sugeriría que es mejor una sociedad en la cual los abogados se ven obligados a defender intereses que pueden perjudicar a los de sus clientes. De ser esta la respuesta correcta, la Corte Constitucional colombiana se habría equivocado al declarar que el secreto profesional es una obligación absoluta y no podría censurarse a Moore, aunque su defensa haya sido en parte responsable de la muerte de Sacco y Vanzetti. No obstante, una conjetura nacida de la lectura de algunos casos jamás podrá ser una respuesta definitiva al problema de qué tipo de intereses deben proteger los profesionales del derecho para lograr el ordenamiento jurídico que mejor logre respetar los derechos de las personas.

Como se mencionó con anterioridad, el segundo tipo de defensa de la tesis de la fidelidad se fundamenta en lo que se ha definido como la división ética del trabajo. Es precisamente esta la justificación que la Corte Constitucional colombiana hace del carácter absoluto del secreto profesional:

La preservación del secreto profesional aparece como una necesidad urgente en las sociedades donde el grado de desarrollo y la complejidad de las relaciones interpersonales e intergrupales, determinan la prevalencia de la solidaridad orgánica (o por desemejanza) sobre la solidaridad mecánica (o por parecido), en términos de Durkheim, pues a medida que se acentúa la división social del trabajo, cada uno de los miembros del conglomerado, que ejerce un oficio específico -y sólo uno-, requiere más del aporte de los otros, para la satisfacción de sus necesidades más apremiantes. Esto por contraste con las sociedades embrionarias donde, en esencia, todos hacen lo mismo y desempeñan a la vez múltiples funciones (Colombia, C411/1993, 2015).

En la serie de televisión House, hay un episodio que describe este argumento (Semel, 2006). Aunque Henry Errington (Howard Hesseman) es un paciente muy viejo para recibir un trasplante de corazón, su médico Gregory House (Hugh Laurie) aboga por él en el comité que autoriza este tipo de procedimientos: "Está diciendo que la vida de un anciano no vale 
tanto como la de un joven" contesta House a aquellos doctores que creen que Henry no merece un corazón nuevo. No obstante, cuando Cameron (Jennifer Morrison), una médica del equipo que dirige House, le pide firmar una apelación para que se reconsidere la decisión, House afirma: "Hicieron lo correcto [...] Estoy defendiendo a mi paciente" 36.

La función que la sociedad le impone a House es la de abogar por los derechos de su paciente, no por los de aquellas personas que se verían perjudicadas si se decide trasplantar el corazón a Henry Errington. De esta forma, la posición del anciano enfermo se ve representada, tiene una voz que al menos será oída en el Comité de Trasplantes, así éste decida que la petición de Henry no es válida. Aun cuando House crea que su paciente no merece el corazón, su función dentro del hospital es velar porque esto suceda y dejar que otros de forma algo más neutral tomen la decisión correcta.

Algo similar puede afirmarse en el derecho. La función de los abogados no es determinar cuáles pretensiones de sus clientes son válidas o cuáles intereses son los que deberían reclamarse en un proceso. $\mathrm{Su}$ obligación se limita a defender los derechos de sus representados y dejar que otros tomen la decisión justa. Si House hubiera buscado la acción que creyera correcta, su cliente se habría quedado sin representación y su voz no sería escuchada en el Comité de Trasplantes. De igual forma, si los abogados solo defienden los intereses que ellos creen legítimos, no existirá nadie que tome la vocería de aquellos sobre los cuales cae una sospecha ${ }^{37}$.

Este tipo de justificación no debe confundirse con la consecuencialista de la cual hablábamos antes. La tesis de la fidelidad, en este caso, no está sustentada en la posibilidad de tener un ordenamiento jurídico más justo, sino en constreñimientos morales propios de la función que los abogados cumplen en la sociedad. Así un Estado fuera mejor de otra forma, se debe

\footnotetext{
${ }^{36}$ Para un estudio sobre las implicaciones éticas de la decisión de House, ver Battaly y Copion (2009).

37 Es posible pensar que en este acápite debe descartarse la analogía entre derecho y medicina, igual que se hizo en la primera parte del capítulo. No obstante, existen al menos una razón que hace esta analogía más válida; House, aunque médico, está cumpliendo funciones legales. En realidad, en el ejemplo estudiado, no está curando o tratando a un paciente sino que está avocando para que se le otorgue un corazón. En otras palabras, la comparación aquí no es entre la medicina y el derecho, sino entre un caso de un doctor que cumple funciones parecidas a las que realizan los abogados.
} 
respetar la fidelidad frente a los intereses de los representados, porque esa es la función que la sociedad les atribuye a los profesionales del derecho.

Quizás la posición correcta sea una intermedia entre la tesis de la fidelidad y la que sostiene que los abogados están obligados con intereses distintos a los de sus clientes. Es cierto que la función primordial de los profesionales del derecho es defender las pretensiones de sus apoderados, no obstante, eso no impide que puedan ampliar los horizontes del caso y utilizar el derecho para fines más altruistas. Tal vez, como en el proceso a Inez García, los abogados tienen la obligación de sugerir una defensa arriesgada para lograr intereses distintos a los que inicialmente concibió el cliente, pero esa estrategia debe ser consentida y acordada entre las partes.

Un caso puede ayudar a una mejor comprensión de esta tesis intermedia. En The Sweet Hereafter ${ }^{8} 8$ (Egoyan, 1997), el abogado Mitchel Stephens (Ian Holm) acude a un pueblo de Canadá, en la Columbia Británica, para apoderar a un grupo de personas que desean demandar a los constructores de un autobús escolar en el que se accidentaron sus hijos. Cuando el caso parece ya ganado, el testimonio de una de las únicas sobrevivientes, Nicole Burnell (Sarah Polley) se dirige en contra de la conductora del autobús, haciendo, de esta forma, imposible ganar el juicio. $\mathrm{Al}$ ser el accidente responsabilidad de la cochera, la empresa manufacturera queda exonerada de cualquier acción que quisieran iniciar las víctimas.

Nicole mintió en la declaración con el fin de vengar el abuso sexual cometido por su padre. Con su testimonio, su violador y el pueblo que permaneció impávido ante su dolor no podrán recibir la indemnización anhelada. Ante la disyuntiva de castigar la violación o recibir la indemnización, Nicole prefiere la primera opción, esa es su silenciosa condena. Esta disyuntiva, sin embargo, es solo aparente. Si su abogado hubiera conversado con ella, habría conocido las inquietudes de sus clientes de forma tal que habrá diseñado una estrategia que lograra la condena de Sam Burnell (Tom MacCamus) y la indemnización que el pueblo necesitaba.

\footnotetext{
${ }^{38}$ La película está basada en Banks (1991).
} 
Este tipo de abogado es por el que aboga Anthony Kronman. Para él, la principal virtud que deben tener los profesionales del derecho es la sabiduría práctica, para lo cual:

\begin{abstract}
los abogados deben ser capaces de combinar las cualidades opuestas de la simpatía y la indiferencia. Aunque algunos, quizás, lo encuentren fácil, la mayoría debe lograrlo a través de un proceso de disciplina y entrenamiento que va en contra del impulso de los más primitivos instintos. El objetivo de este proceso es forzar a la persona que lo sigue a contemplar el mayor número de puntos de vista posible y explorarlos, de modo tal que se profundice la simpatía sin perder el espíritu de indiferencia del cual dependen críticamente los juicios correctos (Kronman, 1993, p. 59).
\end{abstract}

Para Kronman, los abogados deben ser intermediarios entre los intereses públicos y los privados. Debe conocer, por tanto, los hábitos, necesidades y expectativas de sus clientes, y cómo ellos se concilian de la mejor forma con el bienestar general. Si Mitchel Stephens hubiera sido virtuoso, habría conocido de antemano las necesidades de Nicole y le habría sugerido una estrategia que la protegiera de su padre y que, al mismo tiempo, le permitiera recibir los beneficios económicos de la indemnización debida.

En este sentido, la decisión correcta sobre el problema de los intereses que deben defender los abogados depende de cada caso, de cómo es la personalidad y cuáles son las características propias de las personas que se representan. Contario a lo defendido en películas como Adam's Rib, los abogados de antemano no deben utilizar el derecho para cambiar la estructura de la sociedad, sin contar con el consentimiento o el interés de su cliente. Cada caso, sin embargo, debe juzgarse de forma independiente. Es posible, por ejemplo, que la estrategia de Moore fuera correcta para defender a Bartolomeo Vanzetti mas no así para Nicola Sacco. Aunque ambos eran anarquistas, Nicola tenía un carácter débil, propenso a serias crisis nerviosas como las que tuvo durante el juicio. Es plausible pensar que el secreto profesional debe guardarse en el caso de un cliente cleptómano que confiesa robará algún dinero, pero no en el del padre que violaba a su hija en la película Priest. 


\section{CONCLUSIÓN}

Los personajes de abogados son comunes en las películas, algunos de ellos son héroes, otros son villanos. En el drama cinematográfico, se evidencian muchos de los dilemas éticos que afrontan los profesionales del derecho y que, sin embargo, en otros ámbitos pasan desapercibidos. Las voces de los personajes de estas obras nos despiertan del letargo en el que muchas veces se encuentra la Academia respecto a las obligaciones éticas de los abogados 39 .

En este artículo se discutieron dos problemas éticos relacionados con los intereses que deben defender los abogados. En primer lugar, se analizó quién es el cliente cuyos derechos deben protegerse. Al respecto, se describieron las posiciones de quienes sostienen que solo se está obligado respecto de las personas con las que se celebró un contrato de asesoría legal y las de quienes piensan que, en ocasiones, los abogados tienen deberes con personas distintas a sus clientes. En segundo lugar, se estudió el problema de qué tipos de pretensiones deben defenderse. En este sentido, se analizaron las tesis que sostienen que los profesionales del derecho deben proteger intereses de la sociedad y las de aquellos que afirman que los abogados están obligados de forma exclusiva con las pretensiones de clientes. Finalmente, se describió la tesis intermedia, según la cual la función de los profesionales del derecho es, precisamente, conciliar estos intereses mediante la virtud de la sabiduría práctica.

Pese a que se han citado muchas películas, en realidad sólo son dos los filmes que han servido como inspiración de este artículo. Uno es Deck Schiffet en The Rainmaker, para quien la ética legal es una disciplina sencilla que se resume en tres reglas fundamentales. Schiffet no tiene reparos en convertirse en lo que los estadounidenses llaman un cazador de camillas, un tinterillo que acosa a los pacientes en los hospitales hasta que lo contraten para que inicie un juicio. El otro es Frank Galvin, un abogado derrotado que descubre en la fotografía de una víctima no solo la razón de su litigio, sino las fuerzas necesarias para reinventar su vida.

\footnotetext{
39 Entre las pocas excepciones, pueden encontrarse los siguientes libros que discuten problemas de ética legal en nuestro medio: Tobón Franco (2008) y Monroy Cabra (1998).
} 
Guardando las proporciones, el cine puede ser a los profesionales del derecho lo que la fotografía fue a Galvin; un instrumento mediante el cual de forma empática conocemos las vidas de quienes se afectan con el ejercicio del derecho. El arte nos permite descubrir lo que Schiffet ignora, que un paciente no es solo un cliente, es un ser humano que sufre y cuya salud, quizás, dependa del correcto ejercicio de nuestra profesión. El cine nos enseña, igualmente, que el mundo del derecho no es un río prístino de caudal permanente, sino una corriente con meandros y remolinos de la cual dependen la vida y tranquilidad de muchas personas. Por esta razón, porque muchas veces no sabemos cuál es la acción correcta, es necesario preguntarse, ¿Qué intereses deben defender los abogados?

\section{REFERENCIAS}

ACOSTA GÓMEZ, Francisco Javier. Filosofía del derecho privado. Medellín: Señal Editora,1999.

AMERICAN BAR ASSOCIATION. Comments to ABA Model Rules of Professional Conduct. Legal Information Institute. Universidad Cornell. Disponible en: <http://www.law.cornell.edu/ethics/aba/2001/CRule_1.2. htm>. Acceso en: 15 feb. 2015.

BANKS, Russell. Sweet hereafter: A novel. New York: Harper Collins, 1991.

BATTALY, Heather; COPION, Amy Copion. Diagnosticando el carácter: un House dividido? In: IRVING, William; JACOBY, Henry. La filosofía de House: todos mienten. México: Selector, 2009. p. 232-248.

BELLOW, Garry; KETTLESON, Jeanne. From ethics to politics: Confronting scarcity and fairness in public interest practice. In: CARLE, Susan D. (Ed.). Lawyer's ethics and the pursuit of social justice. New York: NYU Press, 2005. p. 136-142.

BIRD, Antonia. Priest. EUA: Miramax Film, 1995.

COHEN, Morris Raphael. The basis of contract. Harvard Law Review, v. 46, p. 571-583, 1933.

COLOMBIA. Corte Constitucional. C-411/1993. Magistrado Ponente: Carlos Gaviria Díaz. Disponible en: <http://www.corteconstitucional.gov.co/ relatoria/1993/C-411-93.htm > . Acceso en: 15 feb. 2015.

COLOMBIA. Corte Constitucional. C-290/2008. Magistrado Ponente: Jaime Córdoba Triviño. Disponible en: <http://www.corteconstitucional. gov.co/relatoria/2008/C-290-08.htm>. Acceso en: 15 feb. 2015.

COMUNIDAD EUROPEA. Consejo de los Colegios de Abogados de la Comunidad Europea (C.C.B.E.). Código Deontológico de los Abogados de la Comunidad Europea . Disponible en: <http://noticias.juridicas.com/base_ datos/Admin/cdccbe.html\#a27>. Accesso en: 15 feb. 2015. 
COPPOLA, Francis Ford. The rainmaker. USA: Paramount, 1997.

CROMPTON, Samuel Willard. The scopes monkey trial. Nueva York: Chelsea House Publications, 2010.

CUKOR, George. Adam's rib. USA: Metro-Goldwyn-Mayer, 1949.

DAMASKA, Mirjan. Presentation of evidence and fact-fanding precision. The University of Pennsylvania Law Review, v. 123, p. 1083-1106, 1975.

EGOYAN, Atom. The sweet hereafter: USA: Alliance Communications Corporation, 1997.

ESPAÑA, Recopilación de Leyes de los Reinos de las Indias, 1841, Título 24, ley $3^{\mathrm{a}}$.

ESPAÑA. Código Civil. Real decreto de 24 de julio de 1889. Disponible en: <http://www.boe.es/buscar/act.php?id=BOE-A-1889-4763>. Acceso en: 15 feb. 2015 .

ESPAÑA, Real decreto 658/2001, "Estatuto general de la abogacía española". Disponible en: <http://noticias.juridicas.com/base_datos /Admin/rd658-2001.html>. Acceso en: 15 feb. 2015.

FINNIS, John. What is the common good, and why does it concern the client's lawyers. South Texas Law Review, v. 40, p. 41-53, 1999.

FRANCIA. Código Civil. Ley de 21 de marzo de 1804. Trad. de Christian Laroumet et al. Disponible en: <www.legifrance.gouv.fr/content /download/1966/13751/.../Code_41.pdf >. Acceso en: 15 feb. 2015.

FREEDMAN, Monroe. Lawyer's ethics in an adversary system. Indianapolis: Bobbs-Merrill, 1975.

FRIED, Charles. Contract as promise. Cambridge: Harvard University Press, 1982.

GABEL, Peter; HARRIS, Paul. Building power and breaking images: Critical legal theory and the practice of law. NYU Review of Law and Social Change, v. 11, p. 369-411, 1982-1983.

GARRY, Charles; GOLDBERG, Art. Streetfigther in the courtroom. New York: Dutton, 1977.

GORDON, Robert. Independence of lawyers. Boston University Law Review, v. 68, p. 1-83, 1988.

GORDON, Robert. Critical legal studies. In: ARTHUR, John; SHAW, William (Eds.). Readings in the philosophy of law. New Jersey: Prentice Hall, 2006. p. 212-220.

GRISHAM, John. The rainmaker. New York: Doubleday, 1995.

HARRIS, John. The survival lottery. Philosophy, v. 50, p. 87-95, 1975.

HART, H. L. A. El concepto de derecho. Buenos Aires: Abeledo-Perrot, 1963.

HUME, David. Tratado de la naturaleza humana. Trad. de Félix Duque. Madrid: Editorial Nacional, 1981.

KAGAN, Shelly. Normative ethics. Colorado: Westview Press, 1998. 
KANT, Immanuel. Fundamentación de la metafísica de las costumbres. Trad. de Manuel García Morente. Madrid: Espasa-Calpe, 1942.

KELMAN, Mark. A guide to critical legal studies. Cambridge: Harvard University Press, 1987.

KENNEDY, Duncan. Notas sobre las historias de CLS en los Estados Unidos. Doxa. v. 11, p. 283-288, 1992.

KRAMER, Stanley. Inherit the wind. USA: United Artists, 1960.

KRAMER, Stanley. Judgment at Nuremberg. USA: United Artists, 1961.

KRONMAN, Anthony. The lost lawyer. Cambridge: Harvard Unviersity Press, 1993.

LARSON, Edward J. Summer for the gods: The scopes trial and america's continuing debate over science and religion. Cambridge: Harvard University Press. 1997

LUBAN, David. Lawyers and justice. Princeton: Princeton University Press, 1988.

LUBAN, David. Legal ethics and human dignity. Cambridge: Cambridge University Press, 2007.

LUMET, Sidney. The verdict. USA: Twenty Century Fox, 1982.

MACKINNON, Catharine A. Toward feminist jurisprudence. Stanford Law Review, v. 34, n. 3, p. 703-737, Feb. 1982.

MILLER, Peter. Sacco and vanzetti. USA: Willow Pond Films, 2006.

MOLINA OCHOA, Andres. Estudios Críticos del Derecho. In: FABRA, Jorge Luis; NUÑEZ VAQUERO, Álvaro. Enciclopedia de de Filosofía y Teoría del Derecho. México: UNAM, 2015. p. 435-458.

MONROY CABRA, Marco Gerardo. Régimen legal y disciplinario del abogado. Bogotá: Ediciones Librería del Profesional, 1998.

MOORE, Fred. Summation of Fred Moore for the defense [1921]. In: LINDER, Douglas (Ed.). The Trial of Sacco and Vanzetti - 1921. University of Missouri-Kansas City, School of Law. Disponible en: $<$ http://law2.umkc.edu/faculty/projects/ftrials/SaccoV/mooresumm.html $>$. Acceso en: 15 feb. 2015.

NAGEL, Thomas. Ruthlessness in public life. In: HAMPSHIRE, Stuart (Ed.). Public and private morality. Cambridge: Cambridge University Press, 1991. p. 75-92.

NEW YORK STATE BAR ASSOCIATION. Statement of Client's Rights. Disponible en: <http://www.nysba.org/Content/NavigationMenu/Public Resources/ClientRightsandResponsibilitiesDeclaracinDeLosDerechosDeLo sClientesyResponsabilidades/Rights.pdf>. Acceso en: 15 feb. 2015.

O'DONOVAN, Katherine. Engendering justice: Women's perspectives and the rule of law. University of Toronto Law Journal, v. 39, n. 2, p. 127-148, 1989.

OSSORIO Y GALLARDO, Ángel. La justicia. Buenos Aires: Ediciones Jurídicas Europa-América, 1961. 
PEARCE, Russell G. Access to justice: Redressing inequality in the market for justice. Frodham Law Review, v. 73, p. 969-981, 2004.

PEREZ LLEDÓ, Juan A. El movimiento critical legal studies. Madrid: Tecnos, 1996.

PITSON, Antony E. Hume on promises and their obligation. Hume Studies, v. XIV, n.1, p. 176-190, 1988.

PLATÓN. La república. Trad. de José Manuel Pabón y Manuel FernándezGaliano. Barcelona: Altaya, 1993.

PRIETO, Guillermo. Lo que nadie sabe de la entrevista con Garavito. Revista Soho, dic. 2006.

ROBBINS, Tim. Dead man walking. USA: Havoc, 1995.

ROSS, W. D. The right and the good. Oxford: Oxford Unviersity Press, 2002.

SEATON, George. Miracle on 34th street. USA: Twenty Centuru Fox, 1947.

SEMEL, David. Sex kills. In House M.D. USA: Bad Hat Harry Productions, 2006.

SEN, Amartya. Elements of a theory of human rights. Philosophy and Public Affairs, v. 32, n. 4, p. 315-356, 2004.

SHAFFER, Thomas L. American legal ethics. New York: Matthew Bender, 1985 .

SHALTER, Kenneth W. (Ed.) The trial of Inez García. Berkeley: Editorial Justa Publications, 1976.

SHERIDAN, Jim. In the name of the father. Irlanda: Hell's Kitchen Films, 1994.

SIMON, William. The practice of justice. Cambridge: First Harvard University Press, 2000.

SINCLAIR, Upton. Boston: A documentary novel. Cambridge: Robert Bently, 1978.

SINNOTT-ARMSTRONG, Walter. How strong is this obligation? An argument for consequentialism from concomitant variation. Analysis, v. 69, n. 3, p. 438-442, 2009.

SIPILLENGER, Clyde. Elusive advocate: Reconsidering brandeis as people's laywer. In: CARLE, Susan D. (Ed.). Lawyer's ethics and the pursuit of social justice. New York: NYU press, 2005. p. 72-78.

TENNESSEE. Criminal Court of Tennessee. The State of Tennessee $v$. John Thomas Scopes, July 21, 1925. Disponible en: <http://law2.umkc.edu/facul ty/projects/ftrials/scopes/scopes.htm>. Acceso en: 15 feb. 2015.

THE LAW: A question of confidence. Time, U.S. Edition, v. 104, n. 1, 1 July 1974.

THIBAUT, John; WALKER, Laurens. Procedural justice. A psychological analysis. Hoboken: John Wiley \& Sons Inc., 1976. 
TOBÓN FRANCO, Natalia. Marketing jurídico. Relaciones con la responsabilidad profesional. Bogotá: Editorial Universidad del Rosario, 2008.

WATSON, Bruce. Sacco and vanzetti: The men, the murders, and the judgment of mankind. New York: Penguin Group, 2007.

Lengua original: Español

Recibido: 17/02/15

Aceptado: 19/10/15 